\title{
Sialyl Lewis-Keyhole Limpet Hemocyanin Conjugate Vaccine
}

National Cancer Institute

\section{Source}

National Cancer Institute. Sialyl Lewis-Keyhole Limpet Hemocyanin Conjug ate Vaccine.

NCI Thesaurus. Code C69000.

A vaccine consisting of the oligosaccharide antigen sialyl Lewis (CA19-9) conjug ated to the nonspecific immunomodulator keyhole limpet hemocyanin (KLH), with potential antineoplastic activity. Upon administration, sialyl Lewis-keyhole limpet hemocyanin conjug ate vaccine may induce production of $\lg G$ and $\lg M$ antibodies as well as trigger an antibody-dependent cell-mediated cytotoxicity (ADCC) against tumor cells expressing the sialyl Lewis antigen. Sialyl Lewis is a blood group antigen and a tumor-associated antigen associated with epithelial cancers such as breast cancer and various digestive cancers. Sialyl Lewis serves as a lig and for the cytokine-inducible cell adhesion molecule (CAM) Eselectin, an endothelial cell-specific type I transmembrane surface protein, thus facilitating hematogenous metastasis by mediating the adhesion of circulating cancer cells to vascular endothelium. 